\title{
OS EXTREMOS DA HISTÓRIA E A VIOLÊNCIA EM WALTER BENJAMIN
}

Jose Gilardo Carvalho ${ }^{1}$

\section{RESUMO}

Para avaliar os desvios sofridos pela história do pensamento na tradição historicista, a filosofia da história de Walter Benjamin concebe uma crítica gnosiológica liberada do continuum pseudológico com o objetivo de salvar os elementos significativos, dispersos, em forma de fragmentos, nas entrelinhas do texto civilizatório, e denunciar a violência da facies hippocratica da historia.

Palavras-chave: Extremos da história. Vencedores. Crítica do conhecimento. Fragmento. Violência.

\section{EXTREMES OF HISTORY AND THE VIOLENCE IN WALTER BENJAMIN}

\begin{abstract}
The philosophy of history of Walter Benjamin conceives an epistemological review released from a deductive pseudological continuum to evaluate the deviation suffered by the history of thought in the historicist tradition, in order to save significant elements dispersed in the form of fragments in between words of the lines of civilization, denouncing the violence of the Hippocratic facies of history which is reflected in Modernity.
\end{abstract}

Keywords: Extreme. Violence. Winners. Critical knowledge. Fragment.

\section{Teoria do conhecimento e continuum pseudológico}

O filósofo judeu, que traz a marca da destruição, da ruína e do estilhaçamento do sentido nos dá o tom de sua filosofia e de seu método, que é desvio (Umweg) nas "Questões introdutórias de crítica do conhecimento", onde se decide pela Representação como a forma genuína da investigação filosófica e a única capaz de deixar que a verdade se apresente. Aqui Benjamin já nos convida ao desvelamento da linearidade da história positiva, quando a enumeração dos acontecimentos históricos em seu caráter unilateral, dogmático e aurático, desafia o leitor a percorrer os labirintos de uma história contada não mais dessa forma, mas reescrita a partir do alegórico, da imagem das ruínas históricas, denunciando todo documento de cultura como

José Gilardo Carvalho é Mestrando em Filosofia no CMAF da Universidade Estadual do Ceará (UECE) e orientado pela professora Tereza Callado. 
documento de barbárie. ${ }^{2}$ Pois a história oficial, positiva, traz em sua imanência a violência naturalizada, institucionalizada, embora de modo mítico, o qual esconde, ou tenta esconder, a perversidade do sistema político e jurídico que Ihe dá sustentabilidade. Ao analisar a história do poder e da violência com o objetivo de pensar esse lado abjeto e doente da civilização Benjamin cria o conceito de facies hipocrática da história. Com o fim de desvelar o que esconde a história oficial, o pensamento benjaminiano se arma de metáforas que representam a sujeição do homem ao sistema, mas contraditoriamente, a tentativa de buscar saídas. A mais importante dela consiste nas restrições ao poder de definição do conceito. Para contornar as perdas que a exclusão do particular acarreta, com o princípio da universalidade conceitual, Benjamin vai priorizar a ideia. "É absurdo ver no universal uma simples média $O$ universal é a ideia". ${ }^{3}$ Ao contrário do conceito, que necessidade de uma constante atualização, só a ideia guarda a verdade de um tempo. Essa verdade não é objetiva. Surge nas entrelinhas do texto, nos fragmentos amontoados e recolhidos pelo "anjo da história", na multiplicidade dos elementos presentes na imagem alegórica da ideia barroca de história. E ela se revela não sem melancolia diante de um mundo de onde migrou o valor. A melancolia está presente no sentido de desesperança, diante da constatação de um mundo mergulhado na imanência, e onde é inútil o apelo à transcendência. $E$ por isso se aferra as imagens na busca de um sentido que the permita transpor 0 sempre igual (das Immer-gleiche) da realidade na Modernidade, concebida como inferno por Baudelaire, conceito acordado por Benjamin. É assim que Benjamin nos leva por sinuosos caminhos, não para nos mostrar saídas, mas para que as encontremos com o pensamento onde todos dizem não haver. Benjamin, não vê nas ruínas, na desolação, uma melancolia que leva a paralisação, à entrega, ao contrário é lá, na imanência da vida real, catastrófica que vamos encontrar a possibilidade no instante do agora, onde toda cognoscibilidade é convocada a realizar a apocatástase histórica ${ }^{4}$, de uma redenção do que está na iminência de ser perdido para a história. Esse

2 BENJAMIN, "Sobre o conceito de história" in: _ Magia e Técnica Arte e Política - Obras Escolhidas I, Tradução Sérgio Paulo Rouanet, São Paulo: Brasiliense, 1985, p. 225.

3 BENJAMIN, Origem do drama barroco alemão, Tradução de Sérgio Paulo Rouanet, São Paulo:Brasiliense, 1985, p. 57

4 BENJAMIN. Passagens, Tradução de WilliBolleetallii, Belo Horizonte: Humanitas, 2006, p. 513. 
momento iluminado de salvação surge para o passado visado pelo presente e por ele redimido. O passado não morreu, não findou, mas permanece aguardando o momento de um agora do pensamento disposto a repensar a história com o objetivo de salvá-la, daí a possibilidade de reescrevermos a história, não mais sob a ótica dos vencedores, mas dos vencidos. Os vencedores, nos alerta Benjamin, continuam vencendo, mas os vencidos podem e devem se aperceber dessa realidade fantasmagórica criada pelo positivismo histórico, mitificador, perverso, que usa ideologicamente da força do mito para fazer da mentira histórica uma falsa "verdade" que não se sustenta quando interrogada. Para Benjamin, a iluminação profana do pensamento e da leitura se encarregará de construiu um outro conceito de história, o que será possível através da leitura imagética da constelação das ideias presentes no desvelamento do mito clássico das formas perfeitas, da linearidade histórica, que quer nos convencer de um progresso histórico (Fortschritt).

Podemos identificar no inicio do Drama Barroco Alemão, o crítico Walter Benjamin. Ele já nos mostra a violência imanente à história oficial, enquanto história que tem uma intencionalidade, a serviço de uma meia verdade. Para Benjamin ela se imanta à perpetuação de uma "média" do universal, como se a média pudesse mostrar ou valer a totalidade, enquanto a média nada mais é do que uma codificação, que esconde as entrelinhas, os desvios, os descaminhos, por onde a verdade surge de modo fortuito. A média é a justificação do mito, da falsa história apregoada por uma classe de privilegiados. Ela pretende dar um caráter único ao múltiplo, ao diverso. Não se constrange em usar a violência e contradição em si mesma, diante uma realidade que traz nas suas artérias expostas a diversidade, a guerra, a morte, enfim as diferenças. É para fazer realçar essas diferenças que se acanham de seus valores que Benjamin vai recorrer à ideia, uma vez que ela "absorve a série de manifestações históricas, mas não para construir uma unidade a partir delas, nem muito menos para delas derivar algo de comum". Benjamin confere veracidade a esse pensamento afirmando que "não há nenhuma analogia entre a relação do particular com o conceito e a relação do particular com a ideia". Para fazer uma crítica à insuficiência do conceito em dizer a totalidade, ele continua: "No primeiro caso, ele (o particular) é incluído sob o conceito e permanece o que 
era antes - um particular. No segundo ele é incluído sob a ideia, e passa a ser o que não era - totalidade" ${ }^{5}$. A alternativa pelo particular salva o pensamento na medida em que evita as generalizações conceituais. .Tanto o método dedutivo como o indutivo degradam as ideias em conceitos, Ao colocar as ideias num continuum, ou seja, em uma cadeia (catenas) de razões, não sobra espaço para o pensamento com sua liberdade criativa. $O$ pensamento assim estrangulado não deixa transpirar a ideia do tempo, que surge da contingência e do acaso. Para representar a ideia Benjamin recorrer ao modelo imagético do mosaico medieval, ${ }^{6}$ cujo esplendor do todo plástico depende de cada fragmento. Cada estilhaço dessa totalidade traz em si a força do particular com sua unidade ${ }^{7}$ que infelizmente desaparece no sistema. A filosofia da história se insurge contra a generalização e a uniformização impostas para o comportamento pelas condições de vida de onde a tradição foi banida, como forma de facilitação em que "abandonamos uma depois da outra todas as peças do patrimônio humano, [tendo] que empenhá-las muitas vezes a um centésimo de seu valor para recebermos em troca a moeda miúda do "atual". ${ }^{8} \mathrm{O}$ atual desvinculado da experiência e dos valores que norteavam 0 comportamento é impregnado do fetiche que trai as relações afetivas entre os homens. Pois o deslumbramento da grande metrópole hipnotiza e debilita o homem moderno, através da técnica sem medida, da técnica pela técnica, no espaço em que o homem se torna um flaneur, alguém que se encanta na metrópole com suas "belezas arquitetônicas, tecnológicas, esquecendo-se dos valores afetivas da existência, tornando-se nessas circunstâncias uma presa fácil das desigualdades sociais, da marginalização, da atomização da consciência e da pulverização dos valores. Benjamin observa que a cultura se transforma em barbárie ${ }^{9}$ a medida que o homem dá as costas para os valores duradouros e se deixa hipnotizar pela novidade inventada pela técnica. Ela possui um arsenal que induz a atitudes mecânicas, num mimetismo a sua própria aceleração, sempre em lances que passam por cima da vontade individual Seus mecanismos segregam na medida em que tentam uniformizar

\footnotetext{
${ }^{5}$ BENJAMIN. Origem do drama barroco alemão. Tradução de Sérgio Paulo Rouanet, São Paulo: Brasiliense, 1984, pp. 68-69. .

6 Idem, ibidem, p. 51.

7 Idem, ibidem, 'p. 52.

8 BENJAMIN, "Experiência e Pobreza" in:__ Magia e Técnica, Arte e Política, Opus cit, p. 119.

9 Idem, ibidem, p. 115.
} 
os gestos, atitudes, comportamentos, modos de agir, porque induzem com 0 expediente da identidade, através da sedução, para a qual atua de forma cruel e perversa, dividindo o mundo entre vencedores e vencidos, o que revela a facies hippocratica da história oficial, escrita sob a ótica dos vencedores. A exigência de uma verdade de caráter único despreza os elementos vivos, isolados em sua contingência diferenciada, donde se conclui que a história linear, na verdade, é um embuste, uma invenção da ideologia do momento em favor de uma elite que se apropria da cultura para torná-la documento de barbárie. Arrancar essa realidade das mãos ávidas dos vencedores é a tarefa da crítica filosófica, que recorre com esse fim a uma crítica do conhecimento que privilegie a ordem das ideias, fazendo com que estas sejam capazes de nomear os fenômenos até então dispersos e não reconhecidos: Com esse objetivo Benjamin tenta desvencilhar do padrão a forma de olhar a humanidade. Repara os vícios do código que rege o comportamento, liberta o pensamento das leis da calculabilidade, no projeto de construção de uma teoria do conhecimento que inclua o periférico, a marginalidade, 0 acaso e 0 imprevisível, como elementos que participam da realidade. Com esse fim liberta-se igualmente do preceito doutrinário imperativo ${ }^{10}$ e vai optar pela representação, como forma de investigação filosófica:

O caminho da verdadeira investigação filosófica, para Benjamin, é a representação. Representação, por um desvio, do universal - a ordem das ideias. Tal Representação não implica nenhuma indiferença quanto ao particular. - a ordem dos fenômenos. Pois essas ideias são em si mesmas opacas e permanecem obscuras, até que os fenômenos as reconheçam e circundem (...) Longe dos fenômenos, as ideias são vazias, do mesmo modo que os fenômenos, longe das ideias estão condenados à dispersão e à morte: dispersão porque não podem agrupar-se em unidades significativas e morte porque estão entregues, sem defesa, ao pensamento abstrato, que as destrói em particularidade ${ }^{11}$.

Para prezar a relação da ideia com a realidade factual, a tarefa do filósofo seria "a de injetar nas ideias o sangue vigoroso da empiria e de salvar os fenômenos, guardando-os no recinto das ideias". Observando que a empiria não pode penetrar diretamente no mundo das ideias, aceita a função

\footnotetext{
${ }_{10}^{10}$ BENJAMIN. Origem do drama barroco alemão, Opus cit, p 51.

${ }^{11}$ BENJAMIN. ODBA, Opus cit, p. 69
} 
mediadora do conceito, que na sua ótica precisa ser revitalizado constantemente. Pelo conceito, "as coisas são divididas em seus elementos constitutivos, e enquanto elementos, podem ingressar na esfera das ideias, salvando-se: Dessa forma não correm o perigo de desaparecem na abstração".

As ideias para Benjamin são como mônadas, cada mônada contém o universal, uma mônada não participa da outra, mas se colocam todas como as estrelas, reunidas em constelações.

A constelação das ideias é rodeada pelos fenômenos que, pela reestruturação do conceito, são salvos e permitem às ideias o brilho do seu caráter universal, assim, os conceitos, de um golpe só, salvam os fenômenos, que, sem eles, seriam destruídos na dispersão de seus elementos constituintes, por outro lado permitem as ideias desvelarem o seu caráter universal.

\section{A facies hippocratica e sua pós-história na modernidade}

Com o objetivo de desentranhar o particular inscrito no viés político do Trauerspiel de dentro das generalizações conceituais do absolutismo do século XVII, Benjamin nos leva à reflexão de um conceito fundamental em sua filosofia da história, a reescrita da história a partir das ideias como mônadas temporais que apontam para sua pós-história. Elas são capazes de desvelar o caráter falido, enigmático de um tempo, para serem decifradas pelo conhecimento de uma época posterior. ${ }^{12}$ Isso se torna possível através do conhecimento acumulado por gerações e guardado no inconsciente. Sabe-se que o inconsciente não se deixa reprimir pela passividade e o conformismo, ao qual Benjamin atribui a supressão da liberdade e a submissão das classes oprimidas. O surrealismo deixa vir a tona o instante de um conhecimento que não se deixou narcotizar como a consciência do homem na modernidade, hipnotizado diante da beleza da mercadoria, cada vez mais inacessível a ele, fomentando o desejo, nunca completamente realizado. Benjamin observa no inconsciente a força do êxtase para implodir o tempo homogêneo e vazio da história dos dominadores em um instante revolucionário do agora, que

\footnotetext{
${ }^{12} \mathrm{O}$ trabalho filológico de Benjamin o leva a descobrir no Trauerspiel uma crítica à teoria da soberania do século XVII, que movimenta a políticaabsolutista. Com base nesses dados o filósofo constroi uma teoria sólida para uma crítica gnosiológica, de onde surgem as"Questões introdutórias de Crítica do conhecimento! publicadas como Prefácio de Origem do drama barroco alemão.
} 
desmitifica a história positivista, alicerçada sobre o mito devastador, perverso, justificador da sociedade dividida em classes antagônicas, criadora do homem narcotizado, coisificado, estranhado, que flaneia pela metrópole sem perceber os fragmentos dos quais ele próprio é um. Vejamos o que nos diz a filósofa benjaminiana Maria Tereza Callado a respeito desse "esvaziamento", em seu artigo: "A Metafísica benjaminiana e o agora (Jetztzeit)", publicado nos Cadernos Walter Benjamin:

"Inspirado n[ess]a carência e na experiência de um tempo fora do tempo, em outras palavras, na manifestação de uma liberdade espiritual, para a qual contribui a leitura de autores surrealistas, irrompe na filosofia de Benjamin, o momento do agora. Ele rasga a crosta da história oficial via historicismo e condensa, de forma monadológica, todos os tempos em um instante messiânico, o instante de cognoscibilidade iluminada.

Para Benjamin convocar todo o conhecimento em favor da libertação da humanidade é fazer jus à intelecção dada por Deus ao homem, pois:

"O que é um homem quando distribui seu tempo, como bens supremos, apenas entre o sono e a alimentação? Um animal, nada mais. Decerto aquele que nos deu tão amplo entendimento, capaz de mover-se entre 0 antes e 0 depois, não quis que essa faculdade e essa razão divina enferrujassem sem uso, dentro de nós"13.

Essa indagação de Hamlet tem eco no pensamento de Lutero, lembra Benjamin no livro sobre o drama barroco, tendo por fim valorizar a capacidade que o homem possui de atuar de forma positiva, no mundo. Essa ação não deixa de repercutir no "agora" de outras épocas, alerta Tereza Callado:

Dessa forma, a pós-história da atemporalidade barroca é inscrita no agora, (Jetztzeit) momento profícuo, pós-aurático, criador, corte no tempo direcionado à realização de uma falsa promessa da ciência equivocadamente absolutizada pela Razão. Trata-se, nessa interrupção, da redenção messiânica da história, em que subitamente a humanidade é salva da utopia da racionalidade, confundida com dominação sobre a natureza, com o aparecimento da máquina, com a exploração do homem pelo homem, do homem pela máquina - um equívoco, pois a máquina não possui tradição nem experiência...

\footnotetext{
${ }^{13}$ BENJAMIN, Origem do drama barroco alemão, Opus cit, pa. 162.
} 
A ação do homem movido pelo conhecimento que é posse se diferencia da ação exercida no momento necessário do "agora" onde se infiltram "os estilhaços do messiânico. Daí a crítica que Benjamin vai fazer a automatização da vida provida pelo tecnicismo que caracteriza a história do declínio do homem identificado à máquina.

\begin{abstract}
É [a] contraversão da história do homem transformado exclusivamente em tecnologia, 0 ponto de vista do conhecimento que é posse (Haben). Trata-se aqui da indenização fraudulenta de uma razão diluída na esteira do conhecimento tecnicista, onde está escrita a história dos vencidos(Unterdruckten). Contra ela surge espontaneamente o agora (Jetztzeit) rebelde à pressão de Cronos - fenda no tempo e dilatação do instante em uma alienação do sofrimento, vontade iluminada e profana, com vistas ao ato de pensar as feridas da história.
\end{abstract}

A expectativa e a grande fé que Benjamin possui na inteligência do homem para encontrar saídas se concentra no seu conceito de "agora do cognoscível (Jetzt der Erkennbarkeit), ${ }^{14}$ imagem dialética capaz de desentranhar a força do pensamento, meio aos obstáculos da inércia e do conformismo, através do apelo à memória e à sabedoria transformada em ação política. Diz Tereza Callado do "agora":

\begin{abstract}
Ele surge meio à tempestade do progresso, ao esquecimento pela velocidade, meio a substituição infernal de jogos de ambição e poder e atua de forma erosiva sobre os monumentos dos opressores. Se o elo perdido do barroco tiver sido o de um conhecimento para o agora, como suspeitamos, o saber apoiado n sabedoria e não apossado pela consciência poderá ter uma origem messiânica.
\end{abstract}

Pelo exposto no artigo da pensadora entendemos que Walter Benjamin, como profundo conhecedor da história da filosofia, da historiografia positivista, da crítica marxista ao sistema hegeliano, não aceita o caráter único, aurático, ideologizado, linear da história contada pelo positivismo histórico. Pelo contrário, Benjamin vê onde todos não vêem ou não querem ver, ou seja, no aparente desprezível, nos cacos da história, no destruído, no destrutível, nas ruínas. É exatamente aí que o filósofo berlinense, visionário vê a possibilidade

\footnotetext{
${ }^{14}$ BENJAMIN. Charles Baudelaire, um lírico no auge do capitalismo - Obras Escolhidas III, Tradução de José Carlos Martins Barbosa, Hemerson Alves Baptista, São Paulo: Brasiliense, 1989, p. 173.
} 
real de uma retomada da história, de uma salvação do que já é dado como perdido. É no obscuro, no absurdo, é nas ruas estreitas e becos de Paris que o Surrealismo redescobre, que Benjamin percebe a chance de recontar a história daqueles cujo nome não figura das autobiografias e livros memorialistas de um tempo. Benjamin potencializa a exclusão recorrendo à poesia de Baudelaire, dedicada às figuras do trapeiro, bêbado, trabalhador, flaneur, prostituta, enfim àqueles que fazem crescer a massa trabalhadora em um heroísmo anônimo. $A$ história das ideias terá que adotar, a partir de Benjamin, o método da imagem dialética, imergindo dos escombros das guerras, dos crimes fratricidas, o outro lado da história que poderia ter sido... com tanto que para isso surja o instante messiânico, o agora, Jetztzeit, através de uma ação do homem para presentificar o passado que é presente. A frágil força messiânica é frágil, mas é messiânica e pode sim permitir aos vencidos reescreverem a história, e recuperarem sua dignidade perdida com a queda do paraíso, na história primeva.

\section{Mito e Poder/violência}

$\mathrm{Na}$ crítica à ciência enquanto se pretende ditadora de uma verdade inquestionável e provedora de uma força unilateral, Benjamin vai vê-la apenas como um aparato conceitual que não diz a verdade, já que a ciência é de per se intencional e para Benjamin a intencionalidade é a morte da verdade. A filosofia benjaminiana não admite a intencionalidade no sistema do conhecimento que é posse (einHaben). Precisamos desvelar nosso olhar embotado pela ciência, pela técnica, pelo pragmatismo, para que nos tornemos capazes de ler a história a partir da ideia, que é universal, de que a história da cultura é a de documentos de barbárie.

Se a ciência estuda fenômenos de forma dicotomizados ela é parcial, intencional, não pode dizer a verdade. Para Benjamin os fenômenos dispersos não passam de meros particulares, de elementos sem constituição. Para isso Benjamin usa do método do desvio (Umweg) para fundar uma teoria de seu conhecimento, liberto das leis da generalização conceitural. Ou seja, é nos descaminhos, nas entrelinhas, na vivência com o choque (Chockerlebnis) da civilização na metrópole da Modernidade, nos absurdos praticados pela "racionalidade" humana, justificados pela historiografia positivista, nas ruínas 
da história, na absurdidade das guerras que Benjamin, percebe a chance da reconceituação dos fenômenos, sua reunião em torno das ideias, desse modo salvar os fenômenos e fazer as ideias universais e constituí-las enquanto uma revolução não sangrenta possibilita uma reescrita da história dos vencidos.

O conceito de representação das ideias permitem perceber a verdade dos oprimidos, não a verdade mítica da história positiva, linear, intencional, mas a verdade que surge, que irrompe dos escombros do que restou após a catástrofe civilizatória.

O poder teorético embutido nas mais diversas ditaduras que se utilizaram da figura do mito para justificar as maiores atrocidades contra 0 homem e a natureza, são exemplos de que não há verdade na história oficial, mas apenas violência. É no paradoxo do discurso oficial de justiça, de harmonia, de paz, de progresso, que Benjamin vai denunciar o "simulacro" da história, na medida em que vão sendo revelados os seus extremos, na crueldade das guerras, na atrocidade dos totalitarismo, antisemitismos, e assim por diante. Ora, aí a questão do conceito é algo sério, pois conceituar é dizer o que a coisa é, mas a historiografia oficial não o diz, utiliza-se dos artifícios da linguagem de propaganda e da sedução das massas, para justificar as atrocidades cometidas em nome de um progresso (Fortschritt) que promete a felicidade a todos mas só cumpre essa promessa à classe dominante. Assim se constrói a verdade mítica, com o apoio de alguns beneficiados. Para reagir a essa realidade Benjamin recorre a um conhecimento que atravessa vários saberes, da teologia à história, da linguagem á arte, como expressão da mentalidade dos tempos. É na imanência das obras, descobertas pelo trabalho do artista individual que elas se tornam ideias, singularidades, evitando o falso universal, que deixa escapar a heterogeneidade, submetendo-a uma classificação a priori, que não mantêm nenhuma relação orgânica com ele. A denúncia a esse método se encontra na teoria do conhecimento de Benjamin, e tem por objetivo salvar o pensamento da generalização conceitual, estigmatizações e simplificações. Ele sugere atentar ao "pormenor do conteúdo material" caso se queira recuperar o que foi perdido na história. Recorre então, em especial, à obra de arte do barroco como pré-história da Modernidade. Vê na dramaturgia barroca a possibilidade de descoberta de uma verdade, pois o próprio drama (Trauerspiel) é uma ideia, E essa ideia é representada pela arte. 
Fiel ao seu programa epistemológico, Benjamin dissocia o drama em seus elementos, isola os aspectos extremos de cada um deles, recolhe-os,sem perder nenhum, e ao completar a descrição do drama como ideia, tem-se uma interpretação objetiva, virtual.

Mas onde estão as ideias? Para Benjamin elas estão na linguagem em sua dimensão nomeadora. Em contraposição a sua dimensão significativa e comunicativa. É a linguagem adamítica que chama as coisas por seu verdadeiro nome, e não a linguagem profana, posterior ao pecado original. A palavra é mero fragmento, coisa entre coisas, degradada num sistema de signos. Assim a palavra perdeu sua capacidade de nomeação e tem agora apenas a função comunicativa. A tarefa do filósofo é resgatar a dimensão nomeadora da linguagem, voltando-se para uma anamnesis, para a condição paradisíaca, em que aquela dimensão reinava sem partilha. Aqui a dialética ideia-fenômeno é idêntica a dialética Nome-palavra, pela qual o filósofo salva a palavra, reconduzindo-a ao Nome, sua pátria original ${ }^{15}$.

A compreensão completa dessas teses exigiria uma remissão à filosofia da linguagem, desenvolvida por Benjamin em outros trabalhos, sob a influência do misticismo judaico. Basta dizer que segundo Benjamin as próprias línguas contemporâneas contêm ecos dessa linguagem adamítica, o que justifica a categoria de anamnesis, recordação: é possível, através da análise da palavra profana, lembrar-se de dimensão nomeadora original, e com isso reconduzi-la, enquanto ideia a ordem do Nome ${ }^{16}$.

Walter Benjamin, no Trauerspiel trata da configuração ambivalente do mundo, apontando que os extremos em que foi escrita a história do homem comporta a violência do poder. A melancolia destilada dessa realidade já se encontra na significação da palavra Trauerspiel, pode ser traduzida como luto e jogo, ou seja, luto diante da existência sem transcendência e jogo para ludibriar a realidade lutuosa. A criatura do barroco vivencia os extremos. Entregue à própria sorte, sente-se perdida, abandonada, desolada, por outro lado ela está

\footnotetext{
${ }^{15}$ Benjamin expõe sua filosofia atrelada à uma teologia subjacente à sua teoria do conhecimento, da ideia como universal, relaciona a melancolia do homem exilado, depois da queda do paraíso, onde a linguagem perde seu caráter nomeador e passa a ter uma dimensão apenas comunicativa. Desse modo Benjamim, revela uma dimensão da mística judaica. E o barroco visto como gênero estético, ideia, é condição de possibilidade de uma redenção platônica das ideias.

${ }^{16}$ BENJAMIN, W. Origem do Drama Barroco Alemão. Trad.pt. Paulo Sergio Rouanet. Brasiliense: 1984, (p. 14-15).
} 
em meio a uma multiplicidade de signos, nomes, objetos, estilhaços, num jogo de elementos dispersos sentidos, que ela busca reunir de modo a formar um sentido.

O Drama Barroco Alemão é, portanto, ideia como imanência da vida e da história, diferentemente da tragédia grega, que possui o caráter mítico, utilizado pela historiografia positivista, linear, que justifica a barbárie como ordem do destino, naturaliza o mítico enquanto verdade, (falsa verdade). Assim o Drama Barroco Alemão, denuncia o caráter mítico da história, sua violência através da sua configuração de ideias. $\mathrm{Na}$ pós história dessa realidade encontra-se o homem da Modernidade arrastado pela tempestade do progresso, construído sobre um tempo homogêneo e vazio do sempre igual da mercadoria. Pois os desvios do conhecimento (que é posse, processado pela consciência) deixou-se legitimar como única forma de saber legitimando através de todos os ramos de conhecimento as diretrizes autorizadas pelos dominadores. Assim atua até mesmo o sistema jurídico, cujos critérios embotam a relação entre meios e fins empregados na busca de seus objetivos, o de normatizar o comportamento, para manipular com mais facilidade as relações entre os homens, sem levar em consideração o particular e o singular. Para salvá-lo a filosofia de Benjamin reage ao poder instituinte e mantenedor do direito, denunciando-o. enquanto poder mítico, ${ }^{17}$ responsável pela legitimação da violência, através do sistema jurídico. Em tom premonitório Benjamin estaria vislumbrando o que aconteceria ao sistema legislativo de Weimar. Nessa Constituição abriu-se um estado de exceção para legalizar os fins, através de meios espúrios. Benjamin menciona duas escolas jurídicas que a violência legítima diametralmente: "lei natural" e "direito positivo". Enquanto o antigo "percebe no uso de meios violentos para fins justos nenhum problema maior do que um homem vê em seu" direito "para mover seu corpo na direção de um objetivo desejado"18, este último, a escola do direito positivo, está mais preocupado com o meio. Benjamin não comunga com nenhuma escola. Mas reconhece o esforço da escola de "direito positivo" para concentrar-se na justificação de meios, como tal, enquanto que a escola do direito natural

\footnotetext{
${ }^{17}$ Documentos de Cultura, documentos de barbárie (Org. e Tradução Willi Bolle) São Paulo: Cultrix, 1986, pp. 160-175.

${ }^{18}$ Ibidem, ibidem, p. 160.
} 
concebe a violência como um quase-orgânico produto "da natureza, como se fosse uma matéria-prima". ${ }^{19}$ No entanto, ambas as escolas, direito natural e direito positivo partilham um erro comum: quando se fala sobre a violência que acreditam no nexo instrumental de meios e fins. "O direito natural visa pela justiça dos fins, "legitimar" os meios, o direito positivo visa "garantir" a justiça dos fins pela legitimidade dos meios ${ }^{20}$. Fica claro no ensaio Crítica da violência (ZurKritik der Gewalt) de 1921 a análise sobre o poder historicamente reconhecido, o chamado poder sancionado e o não -sancionado. Partindo dessa reflexão Benjamin encontra uma perspectiva fora do direito positivo mas também fora do direito natural. É quando apela para uma investigação com a filosofia da história. Ela o auxilia a concluir que "o poder jurídico tende a cercear, através de fins jurídicos, os fins naturais - mesmo em áreas na quais, sem princípio, eles estão livres, dentro de amplos limites, como no caso da educação - a partir do momento em que eles são almejados com um excesso de violência; haja vista as leis sobre os limites de competência de punições educativas. Isso nos leva a ponderar sobre uma distancia entre os termos da legalidade e da legitimidade. Os dois conceitos parecem não coincidir quando se trata de indagar o que é considerado justo de maneira natural e o que é ditado pela convenção. A imposição ideológica é o ponto fulcral que leva Benjamin a questionar a síntese feita por cada época. Ela (a síntese) é concreta e mata o pensamento. Ao se concretizar em uma ideologia - e aqui podemos dar o exemplo da ascensão do nacional-socialismo (nazismo) que assolou o legislativo alemão e estrangulou o destino político daquele país, o pensamento passa a segregar o que não coincide com seus postulados. Esse fenômeno da síntese ideológica será é o ponto de partida da exigência de uma tematização política em Benjamin. Liberar o pensamento do "preceito doutrinário imperativo" significa denunciar, no panorama histórico, a tais descaminhos, com o objetivo de dilatar o compromisso da ação política com a destinação humana.

\footnotetext{
${ }^{19}$ Idem, ibidem, 160.

${ }^{20}$ Idem, ibidem, p. 161,
} 


\section{REFERÊNCIAS}

ADORNO, T./ HORKHEIMER, M. Dialética do Esclarecimento. Trad. Guido Antonio de Almeida. Rio de Janeiro: Jorge Zahar Ed., 1985.

ADORNO, T. Caracterización de Walter Benjamin. In: Sobre Walter Benjamin - Recensiones, artículos, cartas. Madrid: Ediciones Cátedra, 1995.

0 ensaio como forma. In: $\mathrm{COHN}$, G. (Org.) Theodor Adorno. São Paulo: Editora Ática, 1986. (Col. Grandes Cientistas Sociais).

ARENDT, H. Homens em Tempos Sombrios. Trad. Denise Bottmann. São Paulo: Companhia das Letras, 1987.

Entre o passado e o futuro. São Paulo: Perspectiva, 1972.

BENJAMIN, W. Magia e Técnica, arte e Política: ensaios sobre literatura e história da cultura - Obras Escolhidas Volume I. Trad. Paulo Sérgio Rouanet - 7. ed. - São Paulo: Brasiliense, 1994.

Parque Central. In: Charles Baudelaire: um lírico no auge do capitalismo - Obras Escolhidas III. Trad. José Martins Barbosa/Hermenson Alves Baptista - 1르 ed. - São Paulo: Brasiliense, 1989.

Alegoria e Drama Barroco. In: Origem do Drama Barroco Alemão. Trad. Paulo Sérgio Rouanet. São Paulo: Brasiliense, 1984.

. Eduard Fuchs, CollectorandHistorian. In: One-Way Street and Other Writings. [Translators Edmund Jephcott; Kingsley Shorter]. New York: Verso, 1992.

Jesus Aguirre. Madrid: Taurus Ediciones, 1982.

CALLADO, Tereza de Castro. Walter Benjamin - A Experiência da Origem, Col. ArgentumNostrum. Fortalaleza: Eduece, 2006.

, "Onde se esconde o mito?: ensaio sobre linguagem, direito e política em Walter Benjamin" in: Cadernos Walter Benjamin № 08, ISSN 2175-1293Janeiro-Junho de 2012, disponível em www.gewebe.com.br.

CASTRO, E.G. A Aprendizagem da Crítica - Literatura e História em Walter Benjamin e Antonio Candido. Dissertação de Mestrado - Usp (orientador: Prof. Dr. WilliBolle) - São Paulo, 2002.

HABERMAS, J. O Discurso filosófico da modernidade. Trad. Luiz Sergio Repa e Rodnei Nascimento. São Paulo: Martins Fontes, 2002.

HORKHEIMER, M. Teoria Tradicional e Teoria Crítica. Trad. Edgard Afonso Malagodi e Ronaldo Pereira Cunha - 2 ed. - São Paulo: Abril Cultural, 1983. (Col. Os Pensadores). 
Walter Benjamin. Trad. Sônia Salzstein. São Paulo: Brasiliense, 1982. (Col. Encanto Radical).

Por que um mundo nos detalhes do cotidiano? In: Revista Usp, no 15 - Dossiê Walter Benjamin. São Paulo. Disponível em www.usp.br/revistausp/n15/numero15.html. Acesso em 15/12/04.

LÖWY, M. L'AnarchismeMessianique de Walter Benjamin. In: LesTempsModernes. Paris, revuemensuelle, 1983.

. Romantismo e Messianismo - Ensaios sobre Lukács e Benjamin. São Paulo: Perspectiva, 1990. (Col. Debates; v. 234).

MATOS, O. F. O lluminismo Visionário: Benjamin leitor de Descartes e Kant. São Paulo: Brasiliense, 1993.

ROCHLITZ, R. O desencantamento da arte - A filosofia de Walter Benjamin. Trad. Maria Helena Ortiz Assumpção. São Paulo: EDUSC, 2003.

ROUANET, P. S. Édipo e do Anjo. Rio de Janeiro: Edições tempo Brasileiro Ltda, 1981 (Biblioteca Tempo Universitário; 63).

SELIGMANN-SILVA, M. Ler o livro do mundo - Walter Benjamin: Romantismo e crítica literária. São Paulo: lluminuras, 1999. 